\title{
Occupationally related exposures and reduced semen quality: a case-control study
}

\author{
Erik Tielemans, M.Sc., ${ }^{\dagger \dagger}$ Alex Burdorf, Ph.D., ${ }^{\dagger}$ Egbert R. te Velde, Ph.D., ${ }^{\ddagger}$ \\ Rob F. A. Weber, Ph.D., ${ }^{\S}$ Roelof J. van Kooij, Ph.D., ${ }^{\ddagger}$ Hendrik Veulemans, Ph.D.," and \\ Dick J. J. Heederik, Ph.D.*
}

Wageningen Agricultural University, Wageningen; Erasmus University Rotterdam, Rotterdam; University Hospital Utrecht, Utrecht; University Hospital Rotterdam, Rotterdam, the Netherlands; and Catholic University Leuven, Leuven, Belgium

Received July 28, 1998; revised and accepted November 25, 1998.

Supported by the Dutch Prevention Fund (grant 282718) and the Netherlands Institute for Health

Sciences.

Reprint requests:

Dick Heederik, Ph.D., Department of

Environmental Sciences, Environmental and

Occupational Health group, Wageningen Agricultural

University, P.O. Box 238,

6700 AE Wageningen, the

Netherlands (FAX: 31-317-

48-52-78; E-mail: dick

heederik@staff@eoh.wau).

* Department of

Environmental Sciences,

Wageningen Agricultural

University.

+ Department of Public

Health, Erasmus University

Rotterdam.

₹ Department of Obstetrics and Gynecology, University Hospital Utrecht.

$\S$ Department of Andrology, University Hospital

Rotterdam.

" Department of

Occupational and

Insurance Medicine,

Catholic University Leuven.

$0015-0282 / 99 / \$ 20.00$

PII S0015-0282(98)00542-1

Objective: To determine whether there is an association between abnormal semen parameters and occupational exposures to organic solvents, metals, and pesticides.

Design: Case-control study using three case groups based on different cutoff values for semen parameters and one standard reference group.

Setting: University Hospital Utrecht and University Hospital Rotterdam, the Netherlands.

Patient(s): Male partners of couples having their first consultation at the two infertility clinics $(\mathrm{n}=899)$.

Intervention(s): Men provided at least one semen sample. Occupational exposure was assessed with use of job-specific questionnaires, a job exposure matrix, and measurements of metals and metabolites of solvents in urine.

Main Outcome Measure(s): Standard clinical semen analyses were used to define case groups and controls.

Result(s): An association between aromatic solvents and reduced semen quality was demonstrated, irrespective of the exposure assessment method used. The associations were stronger if the case definition was based on stricter cutoff values for semen parameters. Risk estimates were higher if the analysis was restricted to primary infertile men. Exposure to other pollutants at the workplace was not associated with impaired semen quality.

Conclusion(s): The findings indicated an association between aromatic solvent exposure and impaired semen parameters. (Fertil Steril ${ }^{\circledR}$ 1999;71:690-6. (1)1999 by American Society for Reproductive Medicine.)

Key Words: Semen, male infertility, occupational exposures, organic solvents, aromatic solvents

Approximately $15 \%$ of all couples trying to achieve pregnancy have problems with their reproductive function. A male factor is involved in approximately half of these couples (1). In a considerable number of men with abnormal semen characteristics, the etiology is unexplained (1) and may involve unknown environmental or occupational factors. The ability to treat male factor infertility using new assisted reproduction techniques has generated insufficient interest in better understanding the underlying etiologies of male infertility and possibilities for prevention (1).

A few specific occupational exposures, such as the nematocide dibromochloropropane (DBCP) and lead, have long been recognized as risk factors for male infertility (2). So far, however, no chemicals have been associated with effects as strong as those of DBCP. Reproductive toxicity has not been established for the vast majority of chemical agents to which people are exposed.

Semen quality has been studied most often in surveys among working populations using semen analysis to evaluate reproductive function. The participation rate in these studies was often extremely low, typically $25 \%-50 \%$, thus compromising the validity of these studies by the possibility of selection bias (2). Alternatively, infertility clients have been used to investigate the role of occupational factors in male fertility (3-9). These studies allow the 
evaluation of semen analyses at a high response rate. However, the collection of exposure information has typically been limited to a few generic questions. The use of such crude methods can result in an unacceptable degree of misclassification of exposure and underestimation of the relationship between exposure and semen quality or quantity. Thus, lack of association in studies using crude measures of exposure cannot be interpreted as lack of effect (10).

The purpose of this study was to investigate associations between exposure to organic solvents, metals, and pesticides in the work environment and semen characteristics of male partners of infertile couples visiting two infertility clinics in the Netherlands. The obvious need to reduce exposure misclassification led us to ascertain detailed exposure profiles by means of job-specific questionnaires about activities associated with the individual's work setting. In addition, postshift urine samples were collected, and metabolites of specific solvents and urinary metal levels were used as an additional measure of exposure.

\section{MATERIALS AND METHODS}

\section{Selection of Subjects and Semen Analysis}

The study population comprised the males from couples having their first consultation at two infertility clinics in the Netherlands between May 1995 and September 1996. We obtained approval from the institutional review board of both university hospitals. The total number of male subjects who were asked to participate in this study was 1,536 , of whom $1,152(75 \%)$ agreed. Subjects who did not provide a semen sample or those with a pathology unlikely to be caused by occupational exposures were excluded from the study: maldescended testes, history of vasectomy or vasovasotomy, history of chemotherapy, radiation therapy, infections, endocrine hypogonadism, and sexual dysfunction. A total of 899 men were included in the study and delivered a semen specimen.

Semen evaluations in both laboratories followed exactly the same procedures as defined by the World Health Organization (11). Both laboratories are coordinating a large multicentric quality control study among Dutch infertility clinics to enhance the standardization of techniques. Subjects provided a semen sample after an abstinence period between 2 and 7 days.

Three different case definitions were used: [1] a lenient case definition included all subjects with a sperm concentration $<20 \times 10^{6} / \mathrm{mL},<50 \%$ motile sperm, or $<14 \%$ normal forms (Cases A), [2] a stricter case definition included all subjects with a sperm concentration $<5 \times 10^{6} / \mathrm{mL},<10 \%$ motile sperm, or $<5 \%$ normal forms (Cases B), [3] a rigid case definition comprised of individuals with azoospermia (Cases C). The reference group comprised subjects with a sperm concentration of $\geq 20 \times 10^{6} / \mathrm{mL}, \geq 50 \%$ motile sperm, and $\geq 14 \%$ normal forms.

\section{Questionnaires and Exposure Assessment}

Information was collected in several stages. Before the visit to the infertility clinic, subjects were asked to fill in a generic questionnaire about sociodemographic characteristics, lifestyle habits, information concerning previous infertility consultation, time elapsed in trying to conceive, and details of their occupational history. Furthermore, men were designated as having either primary or secondary infertility on the basis of whether they had fathered a child before the time of hospital contact. The information about job characteristics was used to classify subjects a priori as occupationally nonexposed or potentially exposed to organic solvents, metals, or pesticides.

Those classified as potentially exposed were asked to fill in a second, job-specific questionnaire, which was a modified version of the questionnaires developed by Blatter et al. (12). For subjects who refused to fill in a job-specific questionnaire, the exposure assessment was based on generic questionnaire information. Each job-specific questionnaire elicits detailed information on occupational tasks performed, products handled, handling technologies, and frequency of activities.

Those subjects involved in metal grinding or polishing, welding, flame cutting, and soldering were considered exposed to metals. Subjects involved in spraying of pesticides or regularly working on treated crops were considered to be exposed to pesticides. When subjects indicated pesticide exposure according to the job-specific questionnaire, details concerning the type of pesticides were collected subsequently by means of a short telephone interview. The interviewer prompted the subjects to give this information by naming specific trade names anticipated to be present in a particular agricultural setting.

A large number of products and occupational tasks were regarded to result in solvent exposure, e.g., handling of paints or lacquers, adhesives, degreasers, printing inks, and laboratory solvents. Organic solvent exposure occurred relatively often among subjects in this population and was, therefore, evaluated in more detail. In a case-by-case evaluation, exposure to organic solvents in general and exposure to specific classes of solvents (aromatic, aliphatic, oxygenated, and halogenated solvents) was scored on an ordinal three-point scale (i.e., high, moderate, and low or nonexposed). Subjects classified as highly or moderately exposed to solvents were considered to be exposed.

An independent assessment of the exposure to solvents was also made using a job exposure matrix (13). A job exposure matrix can be regarded as a cross-classification of job titles and exposures developed by a team of experts (e.g., chemists or industrial hygienists) that allows exposure to be assessed on the basis of the job title. To reduce exposure misclassification, only subjects classified by this job exposure matrix as highly exposed were considered to be exposed. 
Selected characteristics of cases and controls: the Netherlands, 1995-1996.

\begin{tabular}{|c|c|c|c|c|c|c|c|c|}
\hline \multirow[b]{2}{*}{ Characteristic } & \multicolumn{4}{|c|}{$\begin{array}{l}\text { Percentage of total population with } \\
\text { indicated characteristic }\end{array}$} & \multicolumn{4}{|c|}{$\begin{array}{l}\text { Percentage of primary infertile men with } \\
\text { indicated characteristic }\end{array}$} \\
\hline & $\begin{array}{l}\text { Cases A* } \\
(\mathrm{n}=692)\end{array}$ & $\begin{array}{l}\text { Cases } \mathrm{B}^{\dagger} \\
(\mathrm{n}=267)\end{array}$ & $\begin{array}{l}\text { Cases } \mathrm{C}^{\ddagger} \\
(\mathrm{n}=61)\end{array}$ & $\begin{array}{l}\text { Controls } \\
(\mathrm{n}=207)\end{array}$ & $\begin{array}{l}\text { Cases A* } \\
(\mathrm{n}=542)\end{array}$ & $\begin{array}{l}\text { Cases } \mathrm{B}^{\dagger} \\
(\mathrm{n}=204)\end{array}$ & $\begin{array}{l}\text { Cases } \mathrm{C}^{\ddagger} \\
(\mathrm{n}=49)\end{array}$ & $\begin{array}{l}\text { Controls } \\
(\mathrm{n}=156)\end{array}$ \\
\hline \multicolumn{9}{|l|}{ Age of woman (y) } \\
\hline$\leq 30$ & 49.4 & 55.0 & 62.3 & 44.0 & 55.6 & 62.7 & 65.3 & 50.0 \\
\hline $31-35$ & 37.0 & 34.1 & 26.2 & 39.6 & 34.1 & 30.9 & 26.5 & 36.5 \\
\hline \multicolumn{9}{|l|}{ Education } \\
\hline High school or less & 47.0 & 49.1 & 50.8 & 46.4 & 45.9 & 47.1 & 44.9 & 48.7 \\
\hline More than high school & 53.0 & 50.9 & 49.2 & 53.6 & 54.1 & 52.9 & 55.1 & 51.3 \\
\hline \multicolumn{9}{|l|}{ Previous infertility consultation } \\
\hline None/general practitioner & 66.5 & 65.2 & 68.9 & 67.6 & 65.5 & 61.8 & 63.3 & 65.4 \\
\hline Infertility clinic & 33.5 & 34.8 & 31.1 & 32.4 & 34.5 & 38.2 & 36.7 & 34.6 \\
\hline \multicolumn{9}{|l|}{ Occupation } \\
\hline
\end{tabular}

* Concentration of $<20 \times 10^{6} / \mathrm{mL}$ or motility of $<50 \%$ or morphology of $<14 \%$.

Concentration of $<5 \times 10^{6} / \mathrm{mL}$ or motility of $<10 \%$ or morphology of $<5 \%$.

¥ Azoospermia.

\section{Urine Measurements}

Irrespective of fertility status, 151 subjects who filled in a job-specific questionnaire were selected to deliver a urine sample at the end of a working day. To maximize exposure to organic solvents and metals in this subgroup, we randomly sampled a large proportion of the subjects with potential exposure and a smaller proportion of those who had low exposure or were nonexposed according to the job-specific questionnaire information. A total of 99 cases (86\%) and 27 controls $(75 \%)$ agreed to deliver a urine sample.

All urine samples were analyzed by reversed phase highperformance liquid chromatography (HPLC) for hippuric acid (a metabolite of toluene) and methylhippuric acid (a metabolite of xylene). Analyses of methoxyacetic acid (a metabolite of ethylene glycol monomethyl ether), ethoxyacetic acid (a metabolite of ethylene glycol monoethyl ether), and butoxyacetic acid (a metabolite of ethylene glycol monobutyl ether) in urine were performed by gas chromatography (14). Trichloroacetic acid and trichloroethanol (metabolites of trichloroethylene) were analyzed colorimetrically according to the method of Tanaka et al. (15). The creatinine content of all urine samples was determined with use of the Jaffé method. For hippuric acid, a cutoff point of $1.5 \mathrm{~g} / \mathrm{g}$ creatinine was chosen to discriminate between occupationally exposed and nonexposed subjects (16).

Metal levels were determined in postshift urine samples from 69 cases and 20 controls. Levels of nickel, chromium, cadmium, and manganese were determined with use of atomic absorption spectrometry (Perkin Elmer 5100) with
Zeeman background correction (17-19). Urinary zinc levels were analyzed with use of atomic absorption spectrometry (Perkin Elmer 3100) with deuterium background correction (20). Metal levels were expressed in relation to creatinine levels.

\section{Statistical Analysis}

Adjusted odds ratios (ORs) and 95\% confidence intervals (95\% CIs) were calculated by means of logistic regression analysis. First, we analyzed the data using lenient criteria to define cases (Cases A). Subjects were separated into exposed and nonexposed categories for the various chemical agents. Subjects exposed to a particular agent were compared with all other subjects not exposed to that specific agent. Separate analyses were made for the total study population, for primary infertile men, and for primary infertile men who had never put their reproductive capability to a test or were referred by a general practitioner.

Subsequently, we selected variables with sufficient numbers of exposed subjects for in-depth analyses, using stricter cutoff values for semen parameters (Cases B and C). Metabolites of solvents were used as independent indices of exposure in logistic regression models. Mean urinary metal levels were compared between cases and controls by oneway analysis of variance. The logarithms of urinary metal levels were used in the analyses and back-transformed values were presented.

\section{RESULTS}

Table 1 presents some of the demographic characteristics 
Risk of abnormal semen parameters according to various categories of occupational exposure as assessed by questionnaires.

\begin{tabular}{|c|c|c|c|c|c|c|}
\hline \multirow[b]{2}{*}{ Exposure } & \multicolumn{3}{|c|}{ Total population } & \multicolumn{3}{|c|}{ Primary infertile men } \\
\hline & $\begin{array}{l}\text { No. of exposed patients } \\
\text { in case group } A^{*}\end{array}$ & $\mathrm{OR}^{\dagger}$ & $95 \% \mathrm{CI}$ & $\begin{array}{l}\text { No. of exposed patients } \\
\text { in case group } A^{*}\end{array}$ & $\mathrm{OR}^{\dagger}$ & $95 \% \mathrm{CI}$ \\
\hline Aggregate of all exposures below & 120 & 1.10 & $0.71-1.69$ & 104 & 1.23 & $0.76-1.99$ \\
\hline Organic solvents & 82 & 0.98 & $0.60-1.59$ & 72 & 1.15 & $0.66-1.99$ \\
\hline Aromatic & 55 & 1.27 & $0.67-2.40$ & 49 & 1.92 & $0.88-4.19$ \\
\hline Halogenated & 7 & 2.04 & $0.25-16.80$ & 6 & 1.60 & $0.19-13.51$ \\
\hline Metal exposure & 49 & 1.02 & $0.55-1.90$ & 42 & 1.09 & $0.54-2.19$ \\
\hline Welding fumes & 33 & 1.09 & $0.51-2.34$ & 28 & 1.37 & $0.55-3.39$ \\
\hline Stainless steel & 13 & 0.53 & $0.21-1.37$ & 11 & 0.62 & $0.21-1.84$ \\
\hline Nonstainless steel & 20 & 3.05 & $0.70-13.21$ & 17 & 5.04 & $0.66-38.29$ \\
\hline Metallic dust & 33 & 0.78 & $0.39-1.55$ & 29 & 0.80 & $0.38-1.69$ \\
\hline Fungicides & 9 & 2.68 & $0.33-21.52$ & 8 & 2.54 & $0.31-21.01$ \\
\hline Insecticides & 10 & 1.52 & $0.33-7.06$ & 9 & 1.42 & $0.30-6.79$ \\
\hline
\end{tabular}

Note: $\mathrm{OR}=$ odds ratio; $\mathrm{CI}=$ confidence interval.

$*$ Case $\mathrm{A}=$ concentration of $<20 \times 10^{6} / \mathrm{mL}$ or motility of $<50 \%$ or morphology of $<14 \%$.

† Adjusted for women's age, education, and hospital.

of the different case groups and controls. Partners of controls were older than partners of men with poor semen quality. Cases and controls were similar in other characteristics. A total of $195(91 \%)$ of the subjects completed the job-specific questionnaires, with a similar participation rate for cases and controls.

Exposure to organic solvents, metal fumes and dusts, and pesticides, or a combination of these exposures was not associated significantly with reduced semen quality in the total study population (Table 2). When the analysis was restricted to primary infertile men, the risks were slightly elevated compared with those of the total population. An elevated risk was observed for aromatic solvents, although the $95 \% \mathrm{CI}$ included unity (OR $=1.92 ; 95 \%$ CI: $0.88-4.19$; $P=.10)$

In an alternative analysis with subjects classified as exposed to aliphatic or oxygenated solvents but not to aromatic solvents, no excess risks were shown. Among primary infertile subjects, a dose response was present for aromatic solvents. The OR was 1.61 (95\% CI: $0.69-3.74)$ for moderate exposure and 4.05 (95\% CI: 0.52-31.37) for high exposure $(P$ for trend $=0.07)$. Restricting the population further to primary infertile couples who had never put their reproductive capability to a test or were referred by a general practitioner did not yield different results.

Risks of abnormal semen parameters associated with ar- omatic solvent exposure assessed by different independent methods are shown in Table 3. For primary infertile subjects, risks were elevated clearly for subjects classified as exposed according to the job exposure matrix and job-specific questionnaire approach, and risks increased when stricter cutoff values for semen quality and quantity were chosen. Combining the exposure estimates of both methods yielded the highest risk estimates. The risks decreased when the total population was considered in the analyses. Such in-depth analyses using different case definitions were not possible for metal and pesticide exposure, because the exposure prevalence was too low.

Table 4 shows results for urinary solvent metabolites as independent exposure variables. In 18 cases (18\%) and 1 control (3.7\%) organic solvent metabolites could be detected $(\mathrm{OR}=7.04 ; 95 \%$ CI: $0.83-59.87 ; P=.07)$. In most positive urine samples, hippuric acid or methylhippuric acid was detected. Metabolites of ethylene glycol monomethyl ether, ethylene glycol monobutyl ether, and trichloroethylene could each be found in one urine sample. Metabolites of ethylene glycol monoethyl ether could not be detected at all.

Classifying as exposed only subjects positive for hippuric acid and methylhippuric acid resulted in $17(17 \%)$ exposed cases and $1(3.7 \%)$ exposed control $(\mathrm{OR}=6.80 ; 95 \% \mathrm{CI}$ : $0.79-58.44 ; P=.08$ ). Risks for solvent exposure based on questionnaire information among subjects who delivered a 
Associations of aromatic solvents as assessed by questionnaires and/or job exposure matrix with abnormal semen parameters using different case definitions.

\begin{tabular}{|c|c|c|c|c|c|c|c|c|c|}
\hline & \multicolumn{3}{|c|}{$\begin{array}{l}\text { No. of exposed subjects in } \\
\text { indicated case groups }\end{array}$} & \multicolumn{6}{|c|}{ Odds ratios based on different case groups } \\
\hline & Case $A^{*}$ & Case $\mathrm{B}^{\dagger}$ & Case $\mathrm{C}^{\ddagger}$ & $\begin{array}{c}\mathrm{OR}^{\S} \\
\text { (Case A) }\end{array}$ & $95 \% \mathrm{CI}$ & $\begin{array}{c}\mathrm{OR}^{\S} \\
\text { (Case B) }\end{array}$ & $95 \% \mathrm{CI}$ & $\begin{array}{c}\mathrm{OR}^{\S} \\
(\text { Case } \mathrm{C})\end{array}$ & $95 \% \mathrm{CI}$ \\
\hline \multicolumn{10}{|l|}{ Total population } \\
\hline JEM & 126 & 56 & 17 & 1.14 & $0.74-1.74$ & 1.32 & $0.81-2.18$ & 1.92 & $0.94-3.94$ \\
\hline Discordant & 111 & 47 & 16 & 1.03 & $0.67-1.61$ & 1.18 & $0.71-1.97$ & 1.99 & $0.95-4.18$ \\
\hline Concordant & 35 & 18 & 4 & 1.51 & $0.65-3.50$ & 1.88 & $0.75-4.74$ & 2.25 & $0.60-8.48$ \\
\hline \multicolumn{10}{|c|}{ Subjects with primary infertility } \\
\hline JEM & 106 & 43 & 16 & 1.40 & $0.85-2.31$ & 1.58 & $0.88-2.83$ & 3.37 & $1.47-7.70$ \\
\hline Questionnaires & 49 & 25 & 7 & 1.92 & $0.88-4.19$ & 2.59 & $1.11-6.08$ & 3.23 & $1.05-9.94$ \\
\hline \multicolumn{10}{|c|}{ JEM/questionnaires" } \\
\hline
\end{tabular}

Note: $\mathrm{JEM}=$ job exposure matrix; $\mathrm{OR}=$ odds ratio; $\mathrm{CI}=$ confidence interval.

$*$ Case $\mathrm{A}=$ concentration of $<20 \times 10^{6} / \mathrm{mL}$ or motility of $<50 \%$ or morphology of $<14 \%$.

${ }^{\dagger}$ Case $\mathrm{B}=$ concentration of $<5 \times 10^{6} / \mathrm{mL}$ or motility of $<10 \%$ or morphology of $<5 \%$.

${ }^{\ddagger}$ Case $\mathrm{C}=$ azoospermia.

$\S$ Adjusted for women's age, education, and hospital.

" Discordant: exposed according to JEM or job-specific questionnaires; Concordant: exposed according to JEM and job-specific questionnaires; simultaneously in one model.

urine sample (organic solvents: $\mathrm{OR}=0.92$, aromatic solvents: $\mathrm{OR}=1.25)$ were similar to risks determined in the total study population (see Table 2). Hence, bias resulting from selective forces of participation in the subset of subjects delivering a urine sample is not likely.

Mean urinary metal levels did not differ between cases

\section{TABLE 4}

Associations of solvents as assessed by questionnaires and measurements in urine with abnormal semen parameters among the subset of men delivering a postshift urine sample.

\begin{tabular}{|c|c|c|c|c|}
\hline Exposure & $\begin{array}{l}\text { No. of patients } \\
\text { in case group } A^{*} \\
(n=99)\end{array}$ & $\begin{array}{l}\text { No. of } \\
\text { controls } \\
(\mathrm{n}=27)\end{array}$ & $\mathrm{OR}^{\dagger}$ & $95 \% \mathrm{CI}$ \\
\hline \multicolumn{5}{|l|}{ Questionnaires } \\
\hline Organic solvents & 60 & 16 & 0.92 & $0.37-2.27$ \\
\hline Aromatic solvents & 40 & 9 & 1.25 & $0.49-3.18$ \\
\hline \multicolumn{5}{|l|}{ Measurements in urine } \\
\hline All metabolites & 18 & 1 & 7.04 & $0.83-59.87$ \\
\hline $\mathrm{HA} / \mathrm{MHA}^{\ddagger}$ & 17 & 1 & 6.80 & $0.79-58.44$ \\
\hline
\end{tabular}

and controls (Table 5). On the basis of questionnaire information, 33 cases and 9 controls were exposed to metals, resulting in an OR of 1.28. Again, the risk is similar to that obtained in the total study population (see Table 2), suggesting that selection bias is not present in the subset analyzed for urinary metal levels.

Smokers had significantly higher mean urinary cadmium levels than nonsmokers $(0.26$ compared with $0.18 \mu \mathrm{g} / \mathrm{g}$

\section{TABLE 5}

Mean urine levels ( $\mu \mathrm{g} / \mathrm{g}$ creatinine) of chromium, nickel, cadmium, manganese, and zinc for cases and controls.

\begin{tabular}{lccc}
\hline Element & $\begin{array}{c}\text { No. of patients } \\
\text { in case group A* } \\
(\mathrm{n}=69)\end{array}$ & $\begin{array}{c}\text { No. of } \\
\text { controls } \\
(\mathrm{n}=20)\end{array}$ & $P$ value \\
\hline Chromium $^{\ddagger}$ & 1.37 & 1.29 & .75 \\
Nickel $^{\ddagger \S}$ & 1.53 & 1.35 & .42 \\
Cadmium $^{\|}$ & 0.16 & 0.19 & .42 \\
Manganese $^{\ddagger}$ & 0.52 & 0.56 & .68 \\
Zinc $^{\ddagger}$ & 297.77 & 272.65 & .52 \\
\hline$*$ Case A $=$ concentration of $<20 \times 10^{6} / \mathrm{mL}$ or motility of $<50 \%$ or \\
morphology of $<14 \%$. \\
${ }^{\dagger}$ Determined by $t$-test (urinary metal levels in cases versus controls). \\
${ }^{\ddagger}$ Standardized for subjects of one hospital. \\
${ }^{\S}$ One value among cases was missing. \\
${ }^{\|}$Standardized for nonsmoking subjects of one hospital.
\end{tabular}


creatinine, $P=.02$ ), and mean chromium levels were higher among subjects exposed to stainless steel welding fumes than among other subjects (1.95 compared with 1.41 $\mu \mathrm{g} / \mathrm{g}$ creatinine, $P=.08)$. However, no significant associations were found between other metal exposure variables and urinary metal levels. Metal levels in urine were relatively low, as indicated for instance by the fact that only four urine samples exceeded $5 \mu \mathrm{g} / \mathrm{g}$ creatinine for chromium, and none of the urine samples exceeded $2 \mu \mathrm{g} / \mathrm{g}$ creatinine for cadmium.

\section{DISCUSSION}

This case-control study provides some evidence for an association between aromatic solvents and abnormal semen parameters. The risk estimates increased according to a dose-response trend. Associations were stronger if cases were defined according to stricter cutoff values for semen parameters. The excess risk for aromatic solvents was suggested in the analyses using three independent exposure assessment methods based on job-specific questionnaires, a job exposure matrix, and the determination of organic solvent metabolites in postshift urine samples. As is often the case in community-based studies, the prevalence of most specific occupational exposures was $<5 \%$. Consequently, only exposure to solvents could be subjected to detailed analyses, and, thus, the power to determine other occupational risks was moderate to low in this study.

Aromatic solvents are used extensively in industrial products, such as paints, varnishes, glues, metal degreasers, and in many chemical processes. Depending on the different exposure assessment methodologies that we used, 5\%-15\% of our control subjects were exposed to aromatic solvents. It is, therefore, likely that clinicians will see patients who are exposed occupationally to aromatic solvents in daily practice. A possible relation with spermatogenic disorders can be regarded to be of great public health importance based on this widespread use of solvents.

Occupational exposure to other solvents may have confounded the association between aromatic solvents and semen parameters. Simultaneous exposure to multiple solvents was common among the study subjects. However, subjects classified as exposed to oxygenated and aliphatic solvents and not exposed to aromatic solvents were not at excess risk. Nonetheless, we cannot rule out the possibility that the excess risk in our study was due to correlations of aromatic solvent exposure with some unknown occupational factors.

Exposure to various organic solvents has been associated with decreased semen parameters. An increased frequency of reduced sperm count among workers exposed to glycol ethers has been observed in field surveys (21) and in a case-control study among patients from an infertility clinic (5). However, the number of subjects exposed to these wellknown reprotoxic glycol ethers is probably low in this pop- ulation, because metabolites of glycol ethers could be detected only in a few urine samples. The findings of a recent study provide some support for an association between paternal organic solvent exposure and an increase in time to pregnancy (22). The increased risk could not be attributed to specific solvent classes. Finally, risk of spontaneous abortions was increased among wives of men occupationally exposed to organic solvents in general or toluene in particular (23).

The present study differs from most other case-control studies on male infertility in that special effort was made to evaluate the occupational exposure in great detail. Questionnaires were designed specifically for a particular job and directed at specific work practices related to chemical exposures. This approach is more sensitive than methods based on job titles or generic questionnaires, i.e., harmful occupational exposures are more likely to be identified by this approach than by the less elaborate exposure assessment methods often used in reproductive epidemiology. Because bias from random misclassification of exposure is reduced further by combining two independent but imperfect assessments, the dual assessment of exposure according to the job exposure matrix and job-specific questionnaires resulted in higher risk estimates.

It is of interest that increased risk estimates also were found for urinary metabolites of solvents. Unfortunately, including all subjects in the biomonitoring study was prohibitively expensive. All the postshift urine samples had to be collected at home by a member of the research team because timing of sample collection is of paramount importance when studying metabolites with a short half-life. The potential gain in precision from using biomarkers was, therefore, offset by a decrease in study size resulting from this labor-intensive approach. Hence, interpretation of the biomonitoring results was difficult because of the reduced statistical power to detect an association between exposure and abnormal semen parameters.

The measurements of solvent metabolites and metal levels in postshift urine samples can be regarded as a complementary index of exposure. Measurements in urine provide independent information on both the quantitative and qualitative aspects of exposure experienced by the study subjects, which cannot be assessed by job-specific questionnaires. For instance, urinary chromium levels among subjects exposed to stainless steel welding fumes appeared to be relatively low. It seems not unlikely, therefore, that the levels of metal exposure in this population were below the levels required to produce a detectable increase in risk.

Identifying cases of male infertility within a clinical setting carries a risk for selection bias, because case ascertainment is incomplete. Not all couples with an infertility problem seek medical help (24). If factors related to the decision to seek medical care also are related to occupational exposures, this may result in etiologically irrelevant differences in 
exposure between infertile care-seeking cases and fertile controls who did not seek medical assistance. Moreover, selection patterns might differ across various treatments or investigations; e.g., couples pursuing elaborate procedures such as IVF might not be comparable to couples seeking an infertility workup.

Consequently, to minimize the potential for selection bias we recruited both cases and controls from the same group of couples having their first consultation. Unfortunately, the use of this design may have reduced the generalizability of the study results. Subjects attending an infertility clinic might represent a more susceptible group, thus potentially influencing the relation between occupational exposures and reproductive response.

The presence of selection bias cannot be ruled out completely because care-seeking behavior is not necessarily equal for different types of infertility. The direction and magnitude of this bias, if present, is unpredictable. Nonetheless, the potential for selection bias is expected to be greater for secondary infertile couples because the proportion of care seekers is lowest in this group (24). The higher risk estimates found among primary infertile couples must be given therefore greater credence than those of the total population. An argument can be made for restricting the population further to primary infertile couples without previous detailed infertility workup because this population is expected to be less vulnerable to selection bias. It was reassuring that this exclusion procedure had no substantive effect on the results.

The usefulness of our case-control design might be hampered by the large day-to-day variability of semen parameters. This probably reduces the ability to discriminate between men with normal and abnormal semen parameters in this study population because only one semen sample was available per subject. From this perspective, our approach can be regarded as a conservative strategy that probably attenuates risk estimates (25). Misclassification of subjects according to fertility status could be reduced to some extent by using stricter cutoff points to define cases. However, this approach resulted in small case groups and was feasible only for the analysis of relatively prevalent exposures, such as organic solvents.

In conclusion, this study of patients from two infertility clinics enabled us to evaluate the reprotoxic potential of chemical exposures across a large industrial spectrum in the Netherlands. The number of exposed subjects was low for most substances; therefore, we cannot exclude the possibility of small excess risks for most of the apparently negative associations. Nevertheless, the results indicated an association between aromatic solvent exposure and abnormal semen parameters, irrespective of the exposure assessment method used.

\section{References}

1. Skakkebaek NE, Giwercman A, de Kretser D. Pathogenesis and management of male infertility. Lancet 1994;343:1473-9.

2. Bonde JP, Giwercman A. Occupational hazards to male fecundity. Reprod Med Rev 1995;4:59-73

3. Rachootin $\mathrm{P}$, Olsen $\mathrm{J}$. The risk of infertility and delayed conception associated with exposures in the Danish workplace. J Occup Med 1983;25:394-402.

4. Mortensen JT. Risk for reduced sperm quality among metal workers, with special reference to welders. Scand J Work Environ Health 1988; $14: 27-30$

5. Veulemans H, Steeno O, Masschelein R, Groeseneken D. Exposure to ethylene glycol ethers and spermatogenic disorders in man: a casecontrol study. Br J Ind Med 1993;50:71-8.

6. Lundsberg LS, Bracken MB, Belanger K. Occupationally related magnetic field exposure and male subfertility. Fertil Steril 1995;63:384-91.

7. Gerber WL, De la Pena VE, Mobley WC. Infertility, chemical exposure, and farming in Iowa: absence of an association. Urology 1988; 31:46-50.

8. Effendy I, Krause W. Environmental risk factors in the history of male patients in an infertility clinic. Andrologia 1987;19:262-5.

9. Bigelow PL, Jarrell J, Young MR, Keefe TJ, Love EJ. Association of semen quality and occupational factors: comparison of case-control analysis and analysis of continuous variables. Fertil Steril 1998;69. $11-8$.

10. Ahlbom A, Axelson O, Hansen ES, Hogstedt C, Jensen UF, Olsen J. Interpretation of "negative" studies in occupational epidemiology. Scand J Work Environ Health 1990;16:153-7.

11. World Health Organization. Laboratory manual for the examination of human semen and semen-cervical mucus interaction. 3rd ed. New York: Cambridge University Press, 1993:3-27.

12. Blatter BM, Roeleveld N, Zielhuis GA, Verbeek ALM. Assessment of occupational exposure in a population based case-control study: comparing postal questionnaires with personal interviews. Occup Environ Med 1997;54:54-9.

13. Hoar SK, Morrison AS, Cole P, Silverman DT. An occupation and exposure linkage system for the study of occupational carcinogenesis. J Occup Med 1980;22:722-6.

14. Groeseneken D, van Vlem E, Veulemans H, Masschelein R. Gas chromatographic determination of methoxyacetic and ethoxyacetic acid in urine. Br J Ind Med 1986;43:62-5.

15. Tanaka S, Ikeda M. A method for determination of trichloroethanol and trichloroacetic acid in urine. Br J Ind Med 1968;25:214-9.

16. Lauwerys R, Hoet P. Industrial chemical exposure: guidelines for biological monitoring. Boca Raton, FL: Lewis Publishers, 1993.

17. Veillon C, Patterson KY, Bryden NA. Chromium in urine as measured by atomic absorption spectrometry. Clin Chem 1982;28:2309-11.

18. White MA, Boran AM. Direct determination of nickel in urine by graphite furnace atomic absorption spectrometry. Atom Spectrosc 1989;10:141-3.

19. Herber RFM, Stoeppler M, Tonks D. Cooperative interlaboratory surveys of cadmium analysis in urine. Fresenius J Anal Chem 1990;338: 279-86.

20. Peaston RT. Determination of copper and zinc in plasma and urine by atomic absorption spectrophotometry. Med Lab Technol 1973;30:24953.

21. Ratcliffe JM, Schrader SM, Clapp DE, Halperin WE, Turner TW, Hornung RW. Semen quality in workers exposed to 2-ethoxyethanol. Br J Ind Med 1989;46:399-406.

22. Sallmén M, Lindbohm ML, Anttila A, Kyyrönen P, Taskinen H, Nykyri $\mathrm{E}$, et al. Time to pregnancy among the wives of men exposed to organic solvents. Occup Environ Med 1998;55:24-30.

23. Taskinen H, Anttila A, Lindbohm ML, Sallmén M, Hemminki K. Spontaneous abortions and congenital malformations among the wives of men occupationally exposed to organic solvents. Scand J Work Environ Health 1989;15:345-52.

24. Olsen J, Basso O, Spinelli A, Küppers-Chinnow M. Correlates of care seeking for infertility treatment in Europe. Eur J Public Health 1998; $8: 15-20$.

25. Tielemans E, Heederik D, Burdorf A, Loomis D, Habbema JDF Intraindividual variability and redundancy of semen parameters. Epidemiology 1997;8:99-103. 